\title{
TENDÊNCIAS DAS REFORMAS DA EDUCAÇÃO SUPERIOR NA EUROPA NO CONTEXTO DO PROCESSO DE BOLONHA
}

\author{
Virginia Alonso Hortale* \\ JosÉ-GINÉS MORA*
}

\begin{abstract}
RESUMO: $\mathrm{O}$ artigo traz à discussão as recentes tendências das reformas na educação superior na Europa, iniciadas no século passado. São analisadas suas principais características e de que forma contribuíram para a perda da competitividade e a diminuição da atratividade das universidades em nível internacional e quais foram as respostas dadas pelos atores envolvidos (governantes, docentes e estudantes) visando à renovação de suas estratégias pedagógicas e de gestão para assim atender as atuais demandas de formação para a sociedade do conhecimento. É apresentado o principal componente dessa renovação - a Declaração de Bolonha, assinada no ano de 1999, com seus objetivos, metas, atividades e instrumentos. Ao final, são identificados os problemas na sua implementação, passíveis de retardar o processo, e os desafios a serem superados para alcançar as metas previstas até o ano 2010.
\end{abstract}

Palavras-chave: Educação superior. Reforma. Europa.

\section{TRENDS IN THE HIGHER EDUCATION REFORMS IN EUROPE IN THE CONTEXT OF THE BOLOGNA PROCESS}

ABSTRACT: This paper discusses the recent trends in the higher education reforms in Europe, which started a few years ago. It analyzes their main features, how they contributed to have universities lose their competitiveness and attractiveness at the international level, what were the answers of the stakeholders (government, teach-

* Doutora em Saúde Pública pela Fundação Oswaldo Cruz (Rio de Janeiro). E-mail: virginia@ensp.fiocruz.br

** Doutor em Ciências Econômicas e Empresariais, diretor do Centro de Estudios en Gestión de la Educación Superior, Universidad Politécnica de Valencia (Espanha). E-mail: josegines@upv.es

Educ. Soc., Campinas, vol. 25, n. 88, p. 937-960, Especial - Out. 2004 
Tendências das reformas da educação superior na Europa no contexto...

ers and students) to renew their pedagogical and management strategies and thus respond to recent training demands in the knowledge society. It also presents the major component of this renovation the Bologna Declaration, signed in 1999 -, its goals, activities and tools. It finally points out the problems in its implementation that may delay this process and what challenges should be overcome to attain the objectives set by the year 2010 .

Key words: Higher education. Reforms. Europe.

\section{O contexto histórico}

7 transformação mais importante na história das universidades européias desde o princípio do século XIX é possivelmente o processo de Bolonha, ${ }^{1}$ momento que também marca o término de outro período histórico, dividido em três grandes fases. O da Universidade Antiga, que perdura, com pequenas alterações, da Idade Média até o final do século XVIII, quando as idéias do Iluminismo e da Revolução Francesa dão origem à Universidade Moderna, presente no Estado-nação liberal e que existiu até recentemente. Atualmente se configura um terceiro modelo de universidade, o da Universidade Universal, marcada pela ampliação de seus usuários (passagem de uma educação superior de elite para uma educação superior universalizada), de suas açôes (para responder às necessidades de uma sociedade globalizada) e de seus objetivos (a serviço de uma nova sociedade - a do conhecimento) (Mora, 2001).

A universidade medieval, constituída de uma comunidade de estudantes e docentes que, embora sob proteção da Igreja, de reis ou das cidades onde se estabelecera, era de caráter independente. Do ponto de vista econômico, eram instituições cujos recursos financeiros procediam das propriedades que detinham ou do pagamento dos estudantes. Eram universidades muito pequenas, de natureza privada e administrada de forma autônoma pelos próprios membros da comunidade universitária.

Tal modelo persiste até o final do século XVIII sem alterações, e pode-se dizer que no início do século XIX a riqueza intelectual não era a característica mais marcante das antigas universidades. Na Europa, o Iluminismo, as academias científicas, a Enciclopédia etc. surgem fora do âmbito das universidades, que estavam demasiado apegadas ao Ancient Regime. 
O nascimento do Estado-Nação no início do século XIX significa uma profunda mudança nas universidades. Em todos os países da Europa continental, as universidades, antes privadas, passam às mãos do Estado. Além disso, são obrigadas a enfrentar outro desafio: o da formação de profissionais que a nova era industrial exigia. De duas tendências diferentes surgem dois modelos de universidade: o alemão e o francês. Em 1808 Von Humboldt institui na Universidade de Berlim os princípios do que se chamou "modelo humboldtiano" de universidade. Esse modelo, fruto do idealismo alemão, considera a pesquisa o objetivo básico da universidade. As universidades convertem-se em centros de desenvolvimento científico, controladas pelo Estado no seu funcionamento e financiamento, porém com grande respeito à liberdade acadêmica.

O segundo modelo nasce na França em 1811, com a criação da Universidade Napoleônica. Esta é concebida fundamentalmente como um serviço estatal para satisfazer a necessidade de formar funcionários públicos e promover o desenvolvimento econômico da sociedade, criando uma elite indispensável ao funcionamento do Estado. Os docentes fazem parte do grupo de servidores públicos; não há autonomia universitária, já que tanto seus objetivos quanto o programa curricular são os mesmos em todo o território nacional. Apesar disso, é grande o poder dos docentes universitários, por suas características de classe social de alto prestígio, permitindo-lhes ser particularmente influentes na elaboração dos cursos e na definição da política universitária.

O terceiro modelo de universidade é o anglo-saxão. No Reino Unido, que contava no início do século XIX com somente seis universidades, o Estado não interviu, respeitando suas características medievais. Isso pode explicar o fato de as universidades "públicas" britânicas, irlandesas e canadenses continuarem sendo "privadas" do ponto de vista jurídico. Como a Revolução Industrial demandou a formação de indivíduos mais qualificados, a nobreza e as autoridades municipais em diversas cidades criaram as chamadas "universidades civis" que se expandiram por todo o Reino Unido durante o século XIX. A tradição das antigas universidades, associada ao processo de criação dessas novas universidades, possibilitou que, desde o início, nelas se instaurassem Conselhos de Administração, formados por não-acadêmicos (cidadãos que haviam organizado as universidades). Esses conselhos, presididos por um chanceler, nomeavam o vice-chanceler, ao qual se delegavam todas as decisões da gestão direta das instituições. 
Tendências das reformas da educação superior na Europa no contexto...

As universidades britânicas nunca deixaram de ser autônomas, já que sempre foram de natureza privada. Ao contrário, no modelo europeu continental, é tradicionalmente muito grande o poder do Estado sobre a educação superior, controlando os recursos financeiros, os currículos e a nomeação do quadro docente permanente, que geralmente passa à condição de servidor público. A autonomia institucional nunca existiu ou ficou reduzida ao respeito à liberdade acadêmica. Nesses sistemas, a oligarquia acadêmica (que ocupa o nível mais elevado da pirâmide) detém um grande poder na instituição. É também alto seu poder de influência nos círculos governamentais, pois foram eles que de algum modo conceberam a maior parte das políticas universitárias.

\section{Estrutura da educação superior européia}

No final do século XX, quando o processo de Bolonha teve início, as principais características da educação superior européia não eram tão diferentes do descrito anteriormente. Até recentemente os atributos mais destacados eram os seguintes: ${ }^{2}$

1. A grande maioria das instituições de educação superior é pública. $\mathrm{O}$ número de instituições privadas é elevado, principalmente em alguns países ao sul da Europa; não obstante o número de estudantes matriculados ser proporcionalmente baixo. Somente em Portugal o número de estudantes matriculados em instituições privadas é elevado, porém inferior a 25\% (OCDE, 2003).

2. Na maioria dos países, com exceção dos anglo-saxões, os docentes são servidores públicos e vigoram dois modelos: o germânico e o napoleônico. Em ambos, os docentes com cargo de Professor Titular são servidores públicos estáveis; no entanto, ao passo que no modelo germânico o vínculo de trabalho é estabelecido diretamente com a universidade em que atuam, no modelo napoleônico os docentes fazem parte do quadro de servidores do Estado, propiciando menor integração com a instituição em que atuam (Altbach, 2000).

3. O financiamento dos sistemas universitários é essencialmente público em virtude de duas ordens de fatores. De um lado, o caráter público da maioria das instituições, assim como do quadro docente. De outro, a reduzida integração dessas insti- 
tuições com o ambiente produtivo, fazendo com que o financiamento externo não alcance proporçóes tão altas como nos Estados Unidos da América (EUA). Além disso, as taxas que os estudantes pagam são relativamente baixas, às vezes inexistentes em alguns países (OCDE, 2003).

4. Na maioria dos países, a autonomia das universidades é definida por lei; não obstante essa autonomia seja bastante limitada e reduzida essencialmente à liberdade acadêmica. Em um número relativamente grande de países, excluindo os anglo-saxões, as universidades são subordinadas aos Estados, que regulam seu funcionamento, seu financiamento, seus docentes e os cursos oferecidos (Mora, 2001).

5. Na maioria dos países, as instituições universitárias são administradas pelo quadro docente, pelo pessoal administrativo e pelos estudantes. E isso, associado ao fato de os docentes serem servidores públicos, torna as relações entre as universidades e seu ambiente externo mais frágeis que o desejado. A resposta das universidades às demandas sociais é lenta e fragmentada e, como resultado, insuficiente, já que o poder está nas mãos dos docentes de forma individual.

6. Nos países que seguem o modelo napoleônico (principalmente aqueles ao sul da Europa), os cursos são relativamente homogêneos, excessivamente regulados e de caráter nacional, o que diminui muito a possibilidade de as universidades se diferenciarem e flexibilizarem.

7. Em geral, as carreiras universitárias são organizadas em ciclos únicos de longa duração e possuem um forte componente acadêmico. ${ }^{3}$ Como consequiência desse modelo, o índice de abandono dos cursos é muito alto, sem que aqueles que o abandonaram obtenham um diploma útil para o mercado de trabalho. Além disso, na maioria dos países, o tempo real de duração dos cursos é muito maior que o estabelecido. Ambos os problemas comprovam que os sistemas universitários europeus são pouco eficientes.

8. Embora os sistemas de educação superior de alguns países sejam organizados sob o formato de universidades ou outras ins- 
Tendências das reformas da educação superior na Europa no contexto...

tituiçōes de educação superior, os objetivos institucionais e o plano de ensino dos cursos de graduação variam muito pouco.

No final dos anos de 1990 essa estrutura da educação superior européia já provocava uma série de problemas, sintetizados a seguir:

1. Apesar dos avanços em outros campos, os sistemas de educação superior permaneceram à margem da integração européia. Os tratados da União Européia (UE) especificam que a educação é uma atividade sob jurisdição dos Estados-membros e, portanto, não é matéria de regulamentação. $\mathrm{O}$ objetivo da UE é manter e respeitar a diversidade cultural, considerada um dos valores mais importantes na Europa. Sem dúvida que essa diversidade cultural gera alguns problemas, entre eles a falta de comparabilidade dos sistemas universitários, dificultando a mobilidade tanto de estudantes quanto de graduados.

2. As universidades, tradicionalmente subordinadas ao Estado, seguem sendo dominadas por essa tradição. O peso da demanda, a atenção aos usuários etc. não são prioritários. São sistemas em que freqüentemente predomina a oferta, quando são os próprios docentes que estabelecem o tipo de ensino e seu formato. A transparência das universidades é baixa, como também sua integração com as empresas e a sociedade em geral. São instituições que tendem a se manter isoladas do ambiente externo.

3. Outra conseqüência dessa baixa integração das universidades públicas com a sociedade é o insuficiente financiamento de natureza privada. As universidades européias, se comparadas com as americanas, têm financiamento público semelhante, porém o aporte de empresas e usuários é bem menor, resultando que no seu conjunto têm pior financiamento que as universidades americanas. Ao passo que os recursos destinados a estas alcançam 2,8\% do PIB, na Europa situam-se em torno de 1,2\% (OCDE, 2003). Com isso, as universidades européias oferecem bem menos serviços que as universidades americanas.

4. As universidades, em razão da sua organização (caráter público, docentes do quadro permanente, auto-administração etc.), 
tendem à rigidez estrutural. Seu funcionamento está distante do ideal de uma empresa de serviços em um mundo globalizado e dinâmico. Os especialistas geralmente concordam que a atual forma de gestão da universidade é um grave problema para o seu desenvolvimento em um contexto competitivo.

5. As universidades geralmente sofrem sérios problemas de eficácia e eficiência acadêmicas. Por um lado, há problemas de eficácia, pois, como já mencionado, existe um desajuste entre a oferta educativa (ainda muito ligada às necessidades de uma sociedade industrial) e a demanda da sociedade (cada vez mais relacionada com as necessidades da sociedade do conhecimento). Por outro lado, as universidades não souberam responder adequadamente à nova situação - de uma universidade de massas. O seu tradicional caráter acadêmico de formação corresponde essencialmente a uma universidade de elite, tornando-a pouco atrativa e adequada à multidão de jovens que atualmente nela ingressam.

Todos esses problemas fizeram com que, nos últimos anos, a educação superior européia perdesse competitividade em nível internacional e diminuísse sua atratividade para estudantes de outros países, se comparada com os EUA. Essa falta de competitividade em nível internacional se torna mais aguda nos momentos em que a educação superior passa a ser considerada um bem de natureza comercial, segundo os acordos de governos nas reunióes do GATT, promovidas pela Organização Mundial do Comércio. Da mesma forma, a atratividade para os cursos de pós-graduação é menor que nos EUA, inclusive para os próprios graduados europeus, que em grande proporção preferem estudar nos EUA, com alta probabilidade de que lá permaneçam por vários anos.

Os recursos destinados à pesquisa nos EUA $(2,8 \%$ do PIB, com relação ao 1,8\% da UE) explicam, em parte, a atratividade das universidades americanas para os jovens pesquisadores europeus. Para os próprios europeus, essa atratividade também é baixa e, como resultado, a mobilidade interna na Europa é bem menor que o desejado, apesar do incontestável sucesso do programa de intercâmbio da UE denominado ERASMUS. E, como é obvio, a escassez de recursos contribui negativamente para aumentar essa atratividade. 
Tendências das reformas da educação superior na Europa no contexto...

\section{A resposta política}

A preocupação com os problemas da educação superior motivou os ministros de Educação de França, Alemanha, Itália e Reino Unido, reunidos no ano de 1998 em Paris, a assinarem a denominada "Declaração de Sorbonne", na qual era destacada a necessidade de renovar a educação superior européia para responder às exigências de uma nova sociedade. Essa declaração foi o embrião de uma nova declaração assinada em 1999 por 29 ministros de Educação europeus (não somente os ministros da UE, mas também de outros países europeus), chamada de "Declaração de Bolonha", que deu início ao importante processo de renovação em que hoje estão imersas as universidades (Bologna Declaration, 1999).

É importante destacar que esse processo de renovação não surgiu nas universidades e sim sob o comando dos dirigentes políticos. Temse a impressão de que eles estavam mais conscientes dos problemas da educação superior que a comunidade universitária. Como destacado anteriormente, um dos problemas das universidades européias é seu isolamento da sociedade, e nada mais lógico que a proposta tenha partido de dirigentes dessa sociedade e que estejam liderando esse processo.

$\mathrm{Na}$ Declaração de Bolonha é reafirmada a necessidade de "desenvolver a Europa, fortalecendo sua dimensão intelectual, cultural, social, científica e tecnológica" e que também se deve "assegurar a atratividade da educação superior européia tanto quanto suas tradições culturais". Em resumo, aumentar a atratividade e a aplicabilidade da educação superior para o desenvolvimento da sociedade em seu sentido mais amplo são os princípios que inspiraram a Declaração de Bolonha.

A Declaração de Bolonha estabelece que até o ano 2010 deverá ser consolidado o Espaço Europeu de Educação Superior, com a finalidade de alcançar três objetivos:

1. Aumentar a competitividade e a atratividade em nível internacional da educação superior européia.

2. Melhorar a adaptação da formação dos graduados europeus às demandas do mercado de trabalho.

3. Desenvolver a mobilidade interna e externa de estudantes e graduados. 
Para alcançar esses objetivos, propõe as seguintes metas:

1. Desenvolver um sistema de graus comparáveis e compreensíveis para estudantes e empregadores.

2. Estabelecer uma estrutura de graus em dois ciclos (graduação e pós-graduação), sendo o primeiro relevante para o mercado de trabalho.

3. Estabelecer um sistema uniforme de créditos.

4. Desenvolver programas de intercâmbio para estudantes e docentes.

5. Estabelecer mecanismos de cooperação entre as instituições de educação superior para a garantia da qualidade da formação.

6. Promover a dimensão européia da educação superior.

Convém lembrar a diferença que existe na Declaração de Bolonha entre o que são os grandes objetivos do sistema e o que são as metas para alcançar esses objetivos. Por exemplo, estabelecer uma estrutura de graus baseada em ciclos ou estabelecer um sistema uniforme de créditos são metas para alcançar os objetivos gerais de aumentar a adequação da educação às necessidades reais da sociedade ou, utilizando as próprias palavras da Declaração, "melhorar a adaptação da formação dos graduados europeus às demandas do mercado de trabalho". O que alguns chamaram de "demônio dos detalhes" (Berlin-Bologna, 2003) produziu alguma desorientação, já que para muitos as metas se converteram em objetivos. Ouve-se freqüentemente que a mais importante alteração realizada no processo de Bolonha foi a organização do sistema de graus em dois ciclos. No entanto, isso não teria valor se não tivesse ocorrido uma sensível melhora na qualidade da educação superior européia, que é a única base sólida para aumentar a atratividade em nível internacional e melhorar a adaptação da formação dos graduados europeus às demandas do mercado de trabalho.

A Declaração de Bolonha foi reforçada pelas declarações do Conselho Europeu (instância decisória máxima da UE), que afirmou a necessidade de fortalecer e renovar a educação superior e a pesquisa na UE. Por exemplo, no ano de 2000, em reunião em Lisboa, o Conselho Europeu indicava que para o ano 2010 a UE "deveria converter-se na economia mais competitiva e dinâmica do mundo, baseada no conhe- 
Tendências das reformas da educação superior na Europa no contexto...

cimento" (União Européia, 2000). Na reunião do Conselho Europeu em Barcelona, em 2002, declarou-se que "a educação européia deverá ser uma referência mundial para 2010” (União Européia, 2002). E não somente a educação como também a pesquisa deveria experimentar um notável progresso, para o qual o Conselho se comprometia a investir em pesquisa e desenvolvimento até 3\% do PIB da UE. Embora ambas as declarações sejam excessivamente otimistas, mostram um compromisso político com a melhoria da qualidade da educação superior e da pesquisa, requisito indispensável para aumentar a competitividade em nível internacional das universidades européias.

É importante destacar que a Declaração de Bolonha (e suas atividades posteriores - processo de Bolonha) não está no âmbito estrito da UE, pois foi elaborada por um conjunto de ministros da Educação europeus, e não tem valor legal em nível europeu. Portanto, não se caracteriza como um mandato da UE que obriga os países-membros ao seu cumprimento; é um acordo que só tem validade se os governos signatários o implementarem em seus respectivos países. Na realidade, a legislação da UE impede o estabelecimento de normas uniformes na área da educação, já que esta está sob tutela exclusiva dos Estados-membros. Em contrapartida, nem todos os ministros da Educação signatários (inicialmente 29 e posteriormente 40) são membros da UE. Sem dúvida que, desde o primeiro momento, a UE desempenhou um papel de liderança no processo de Bolonha, já que um grande número de atividades e de projetos desenvolvidos no marco desse processo foi financiado e liderado por instituições da UE. Poder-se-ia dizer que o processo de Bolonha é um processo de todas e de cada uma das nações européias em que a UE atua como dinamizadora.

Após a Declaração de Bolonha, passou-se por um período de intensa atividade política e universitária. Para implementar o processo, foram constituídos grupos de trabalho tanto nos ministérios como nas universidades. Um dos acontecimentos mais relevantes foi a reunião das universidades européias, realizada em Salamanca, no ano de 2001 (Mensaje de Salamanca, 2001), que supunha a concordância formal das universidades ao processo de Bolonha. Não foi um simples acordo, mas a resultante de extensas e profundas discussões sobre os princípios e objetivos da Declaração de Bolonha. Alguns fatores dificultavam a concordância plena das universidades, como resume de forma perfeita a seguinte frase do comunicado final da reunião de Salamanca: "As uni- 
versidades européias desejam assumir a responsabilidade de atuar em um contexto competitivo para a educação superior, contudo isso requer mais independência de gestão, um marco regulador mais flexível, mais financiamento e maior autonomia". A resposta das universidades foi a de aceitar o novo marco, porém reclamando maior liberdade. Não sem razão, pois, como assinalado anteriormente, um dos mais graves problemas das instituições de educação superior européias é a rigidez estrutural que as impede de atuar adequadamente em um contexto competitivo, porque carecem de maior liberdade e flexibilidade para planejar, distribuir recursos, contratar professores, fixar regras de admissão de alunos ou definir os cursos.

Em 2001, os ministros de Educação tornaram a se reunir em Praga para analisar como estava o desenvolvimento do processo de Bolonha e decidir novas estratégias. O comunicado final dessa reunião confirmou o processo de dois anos decorridos entre Bolonha e Praga. Foi um resultado que ultrapassou as expectativas, dado o grande volume de discussões, muitas delas por divergências de fundo. O Comunicado de Praga (2001) significa a confirmação e a concordância de governos e universidades em dar continuidade ao processo definido dois anos antes. A partir desse momento, pelo menos oficialmente, ninguém discutirá mais a pertinência ou não do processo de Bolonha.

E é exatamente a partir dessa reuniāo que associações profissionais e estudantes iniciam formalmente sua colaboração para a implementação do processo de Bolonha. Numerosos projetos, alguns dos quais serão citados mais adiante, começaram a ser desenvolvidos e, para a subseqüente reunião dos ministros de Educação realizada em Berlim em 2003, foram elaborados documentos, relatórios e declarações das instituições, possivelmente em excesso. Como essa riqueza de análises e documentos produziu um efeito pouco operacional, o comunicado final da reunião de Berlim (Berlin Communiqué, 2003) é mais que uma declaração de princípios, é um conjunto de fatos e propostas. Em alguma medida o "demônio dos detalhes" afetou negativamente o processo; não obstante o comunicado ratificar todos os termos da declaração original e propor acelerar o processo para alcançar algumas das metas, como, por exemplo, iniciar em 2005, em todos os países, a estrutura de graus em dois ciclos.

A Associação Européia de Universidades reuniu-se em Graz antes da reunião de Berlim (2003) e na sua declaração final reafirmou o 
Tendências das reformas da educação superior na Europa no contexto...

pleno apoio ao processo de Bolonha, no entanto com algumas nuanças importantes. Em primeiro lugar, as universidades declararam que a educação superior na Europa continuaria sendo de responsabilidade pública. Esse é um aspecto importante, posteriormente aceito pelos ministros, e que impede uma hipotética mercatilização da educação superior européia.

Em segundo lugar, as universidades insistiram em que a pesquisa é parte integrante da educação superior, reafirmando o estreito vínculo que deve existir entre pesquisa e aprendizagem. Essa afirmação, bastante polêmica em um sistema de educação superior de massas, trata de evitar a criação de instituições de educação superior voltadas exclusivamente para o ensino e afastadas da investigação. Outro aspecto interessante da Declaração de Graz é a autocrítica das universidades sobre sua forma de organização. Seus líderes reconheceram que as reformas requerem mudanças no atual formato de gestão e administração. Textualmente afirmaram que "as reformas requerem liderança, gestão estratégica e qualidade em cada instituição".

Por último, e antes de apresentar as recentes tendências desenvolvidas por alguns países promovendo a acreditação dos cursos de graduação, as universidades européias insistiram em que a garantia de qualidade da educação superior deva ser um processo interno.

Os estudantes europeus, por intermédio de suas associações, também estão participando do processo. Em um comunicado publicado após reunião em Gotemburgo, em 2001 (ESIBs, 2001), manifestaram seu pleno apoio ao processo de Bolonha destacando, porém, a necessidade de se dar mais atenção ao impacto desse processo na sociedade. Neste sentido, insistiram na importância da eqüidade no acesso à educação superior e suas implicaçôes sociais e civis. Além disso, reclamaram participar mais ativamente do processo, como de fato aconteceu desde então.

\section{As metas do processo de Bolonha}

Como já citado anteriormente, são três as metas do processo de Bolonha: aumentar a competitividade, melhorar a adaptação ao mercado de trabalho e desenvolver a mobilidade. O significado de cada uma dessas metas é analisado com mais detalhe a seguir. 


\section{Competitividade}

No processo de Bolonha, competitividade é sinônimo de atratividade. É muito clara a perda relativa de atratividade da educação superior européia para estudantes e pesquisadores de outros países, especialmente quando comparada com os EUA. A meta é melhorar a posição estratégica da educação superior européia em nível mundial, de forma que ela seja mais atrativa para os próprios europeus e para a comunidade internacional.

pode ser alcançada por meio de uma política de melhora como também com o aumento da visibilidade do que é oferecido nas instituições de educação superior européias. É evidente que a melhora da qualidade é a primeira condição para aumentar essa atratividade. Esta deve ser resultado de múltiplas ações: melhora dos serviços oferecidos aos estudantes nas instituições, cursos mais estimulantes e adaptados às demandas sociais, ajuste nos planos de ensino para terem um tempo de duração real, diversidade da oferta para satisfazer as múltiplas demandas sociais e melhora de todos aqueles aspectos da educação superior européia menos atrativos que nos outros sistemas de educação superior. Quase tão importante quanto a melhora da qualidade deve ser o aumento da visibilidade, incluindo a transparência e a informação sobre as instituiçõos e sobre os cursos oferecidos.

O processo de Bolonha propõe concretamente algumas medidas para aumentar a atratividade da educação superior européia. A primeira, que os diplomas sejam compreensíveis quer para empregadores como para estudantes de qualquer lugar do mundo. A segunda, apresentarem de forma explícita os conteúdos aprendidos durante a permanência do estudante na universidade, entendendo que estes não devem ser somente os conhecimentos adquiridos como também as competências gerais (habilidades e atitudes) necessárias ao mercado de trabalho e à vida pessoal. No processo de Bolonha também é proposto, como não podia deixar de ser, incrementar a quantidade e melhorar a qualidade dos serviços oferecidos aos estudantes. Por último, recomenda-se o desenvolvimento de programas transnacionais. Na prática já está sendo facilitada a criação de cursos conjuntos de segundo ciclo (mestrado e doutorado) entre universidades européias e de outros países, mediante programas de apoio a estudantes que queiram inscrever-se em tais cursos. 
Tendências das reformas da educação superior na Europa no contexto...

\section{Adaptação às demandas do mercado de trabalho}

Como assinalado anteriormente, um dos problemas da educação superior européia é seu distanciamento do novo mercado de trabalho da sociedade do conhecimento. Neste sentido essa proposta vem a ser entendida como uma exigência de ensinar e aprender o que é relevante para o mercado de trabalho; e que as instituições de educação superior devem dar respostas às novas demandas sociais e não seguir atendendo a modelos obsoletos, que só se mantêm em razão da inércia do sistema. É também uma proposta que, além de qualificar para as necessidades da nova sociedade, reconhece mediante um claro sistema de avaliação que os resultados pretendidos foram alcançados.

Os fatores decisivos para melhorar a adaptação às demandas do mercado de trabalho são: definir claramente os objetivos de aprendizagem de cada curso, elaborar as competências (conhecimentos, habilidades e atitudes) necessárias para realizar uma determinada atividade profissional e para o desenvolvimento pessoal, e estabelecer um claro sistema de garantia de qualidade dos programas de ensino que assegurem que aquelas competências são as verdadeiramente adquiridas pelos graduados daqueles cursos.

O que o processo de Bolonha propõe para isso é um novo modelo educativo que supere o do século XIX, ainda em vigor, e reforce a aquisição de um conhecimento científico amplo bem como a capacidade para aplicar esse conhecimento. Significa formar nas chamadas competências transversais, dentre as quais destacamos o aprendizado, conseguido não apenas por meio das fontes tradicionais, mas também da própria experiência, da de outras pessoas e das inovaçóes científicas e tecnológicas.

\section{Mobilidade}

A terceira grande meta do processo de Bolonha é o desenvolvimento da mobilidade interna e externa para estudantes, docentes e pessoal administrativo. Essa proposta parte de dois pressupostos. O primeiro, que um amplo mercado competitivo para a educação superior servirá para melhorar a qualidade das instituições européias; e o segundo, que é necessário desenvolver a cidadania européia por meio do profundo conhecimento de outros países e culturas. Para sua viabilidade, 
torna-se necessário que as estruturas educativas nos diferentes países sejam passíveis de comparação a fim de tornar possível o reconhecimento de cursos concluídos em outro país. E respeitar a diversidade significa que a comparação deva ser baseada em um modelo flexível que reconheça quer os conhecimentos básicos transmitidos por outros sistemas educativos, quer a qualidade de outras instituiçóes.

Para a implementação dessa proposta, foi criado em 1988 o programa ERASMUS (1988), que mobilizou até hoje mais de um milhão de estudantes europeus. Por meio desse programa, a UE concede apoio econômico aos estudantes que desejam estudar durante um semestre letivo em outro país da UE. Esse apoio não cobre todos os gastos, porém o que torna o programa atrativo é o fato de as instituições que recebem os estudantes terem a obrigação de tratá-los como seus próprios estudantes e facilitar-lhes a integração na instituição. Em contrapartida, a instituição de origem tem a obrigação de reconhecer os créditos de disciplinas/cursos concluídos naquele semestre na universidade estrangeira. Pesquisas realizadas com os estudantes que participaram desse programa mostram um altíssimo nível de satisfação. Uma pesquisa recente comprovou que $84 \%$ dos estudantes ERASMUS estavam bastante ou muito satisfeitos com a experiência acadêmica, e esse nível de satisfação alcançou 98\% quando se perguntou sobre a experiência social e cultural. Esse programa de intercâmbio de estudantes é possivelmente o de maior sucesso na Europa para o desenvolvimento da cidadania européia.

O sucesso do programa e a necessidade de ampliar essa mobilidade criaram as condiçôes para a elaboração de um novo programa de intercâmbio, não restrito aos cidadãos da UE. Trata-se do programa ERASMUS Mundus (2004), cujo objetivo é realizar intercâmbio de estudantes de todo o mundo mediante apoio financeiro para fazer cursos de segundo ciclo nas universidades européias ou em universidades associadas de outros países. A importância desse projeto pode ser percebida pelos recursos que lhe foram destinados para o período 2004-2008 e que alcançarão o valor de 230 milhôes de euros.

\section{Alguns instrumentos do processo de Bolonha}

Alguns dos mais importantes instrumentos no processo de Bolonha e que despertaram grande interesse dentro e fora da Europa são: o Suplemento do Diploma, os créditos europeus (ЕСTS) e a estrutura dos 
Tendências das reformas da educação superior na Europa no contexto...

graus em ciclos. A seguir é visto com mais detalhes em que consiste cada um deles.

O Suplemento do Diploma (2003) é um documento que será anexado aos diplomas das universidades a partir de 2005. Nele serão informadas as características da universidade em que o estudante concluiu o curso, o programa e os objetivos de aprendizagem do programa, informando-se também os conceitos recebidos pelo estudante. Seu objetivo é informar a possíveis empregadores europeus ou de outros países o tipo e o nível da qualificação recebida pelo graduado.

Outro instrumento generalizado no processo de Bolonha é o dos créditos europeus (European Credit Transfer System - ECTs) (2003). É anterior a esse processo, já que foi elaborado como um sistema de avaliação dos cursos para facilitar a implementação do programa ERASMUS. A novidade é sua ampliação a todos os cursos de todas as instituições de educação superior européias. A idéia-chave na definição é que os créditos do curso não são baseados nas horas de docência do professor, como é tradicional, mas nas horas de trabalho-padrão de que um estudante necessita para adquirir as competências que lhe foram definidas previamente em cada disciplina. $\mathrm{O}$ sistema estabelece que um crédito é equivalente a 25-30 horas de trabalho do estudante (permite-se uma certa flexibilidade na definição exata dos créditos), e que um ano acadêmico deve representar um total de 60 créditos. Assim, se o curso estiver adequadamente concebido, um estudante "normal" não deverá se atrasar para concluí-lo.

Talvez o mais conhecido instrumento elaborado no processo de Bolonha para facilitar a comparabilidade dos graus nas estruturas educativas européias seja o da estrutura de dois ciclos. Tradicionalmente, a maioria dos cursos europeus é de longa duração (em torno de cinco anos), e, na prática, é maior o tempo que os estudantes levam para concluir satisfatoriamente o curso. A proposta do novo sistema é estabelecer dois ciclos: o primeiro com uma carga de 180 a 240 créditos (entre três e quatro anos de duração), e o segundo ciclo entre 60 e 120 créditos (um ou dois anos de duração). O total de créditos necessários para obter o grau de segundo ciclo é de 300 créditos.

Cada instituição, cada país ou cada curso poderá definir essa estrutura de forma distinta, porém dentro dos limites propostos. Uma condição requerida é que o diploma do primeiro ciclo deva ter relevância para 
o mercado de trabalho, ou seja; não deva ser a simples divisão de um curso de longa duração em dois períodos mais curtos, e sim realizar uma verdadeira transformação curricular que permita a entrada no mercado de trabalho daqueles que concluíram o primeiro ciclo. Alguns cursos como medicina, arquitetura ou veterinária são excluídos dessa estrutura, já que serão sempre organizados como cursos de longa duração.

Como já destacado, o processo de Bolonha não tem caráter obrigatório, a não ser que os governos dos países participantes decidam implementá-lo. Em alguns países, como, por exemplo, França e Alemanha, os governos decidiram dar liberdade para as instituições estabelecerem ou não uma estrutura de ciclos em seus cursos, podendo haver a convivência (possivelmente por muito tempo) de cursos renovados com cursos do sistema anterior. O futuro dirá qual modelo terá maior sucesso entre os cidadãos e o mercado de trabalho.

\section{A garantia de qualidade no processo de Bolonha}

Uma das idéias-chave do processo de Bolonha e que, na prática, perpassa todas as suas metas é a exigência de estabelecer um sistema de garantia de qualidade eficaz e que possa ser reconhecido pelo conjunto dos países europeus e de outros países. Na Europa, os processos de avaliação da qualidade começaram a ser implementados durante os anos de 1980 e nos anos de 1990 praticamente todos os países estruturaram agências nacionais ou regionais para realizar avaliação de qualidade das instituições de educação superior.

Em 1998, a Comissão Européia publicou um documento recomendando o estabelecimento de sistemas nacionais de garantia de qualidade bem como a estruturação de algum tipo de coordenação em nível europeu. A partir dessa recomendação, foi criada em 1999 a European Network for Quality Assurance in Higher Education (ENQA), uma rede de mais de 40 agências européias responsáveis por processos de qualidade em seus Estados e regióes e que tem participado intensamente no desenvolvimento do processo de Bolonha. Embora estejam sendo desenvolvidos projetos comuns de caráter transnacional, o objetivo da rede não é estabelecer uma agência européia ou processos comuns de garantia de qualidade. Ao contrário, o objetivo é desenvolver a confiança mútua entre as diferentes agências, para que cada uma delas tenha 
Tendências das reformas da educação superior na Europa no contexto...

segurança do que a outra realiza e que, no futuro, o reconhecimento da qualidade de uma instituição de educação superior realizado por uma agência possa ser aceito pelo conjunto das agências européias.

Recentemente, como conseqüência do processo de Bolonha e da pressão de alguns estados europeus, surgiu a idéia da acreditação na Europa (Berlin Communiqué, 2003). A acreditação tem tradicionalmente sido desenvolvida ao largo da educação superior, em razão do seu caráter altamente centralizado; não tendo sentido para os Estados que controlam excessivamente as instituições universitárias exigirem algum tipo de acreditação externa. Essa situação vem pouco a pouco se alterando, em virtude da crescente autonomia das universidades e, principalmente, da necessidade de se estabelecer algum tipo de reconhecimento internacional do nível de qualidade das instituições européias.

Uma das exigências do processo de Bolonha é que a formação recebida pelos graduados seja reconhecida, o que se pode fazer por intermédio de processos de garantia de qualidade internos, como demandado pelos representantes das universidades européias, ou por meio de acreditação externa, que está sendo implementada em alguns Estados europeus como os Países Baixos, a Bélgica e a Espanha, os mais destacados nesse processo. Recentemente foi criada a rede européia para a acreditação (European Consortium for Accreditation - ECA), com o objetivo de compartilhar metodologias e experiências. Como o futuro da acreditação na Europa ainda é incerto, supõe-se que as carreiras de natureza mais profissional sigam esse caminho. $\mathrm{O}$ menos provável, porém, é que a acreditação se converta em um sistema difundido em todos os países europeus, por causa, entre outras coisas, do elevado custo de seus processos. É bem provável que procedimentos de auditoria de qualidade (comprovação se a instituição possui sistemas internos de garantia de qualidade) sejam implementados em nível institucional, ao passo que os de acreditação de cursos somente o sejam nos cursos profissionais, nos quais se necessita garantir com maior rigor a aquisição de um nível de conhecimentos mínimos.

\section{Alguns projetos relevantes}

Nos últimos anos foram implementados alguns projetos que contribuíram com o desenvolvimento do processo de Bolonha. A seguir é feita uma breve descrição dos mais relevantes. 
1. Projeto Tuning (2001) - desenvolvido por um conjunto de universidades, com financiamento da UE. Tem como objetivo definir as competências necessárias ao graduado em um número pequeno de carreiras. Grupos de trabalho para cada carreira elaboraram as competências (conhecimentos, habilidades e atitudes) que deveriam ter seus graduados. Também foi feita uma ampla pesquisa entre graduados, empregadores e docentes para conhecer as opiniões desses três grupos com relação às competências que deveriam ser adquiridas. $\mathrm{O}$ resultado desse projeto, atualmente numa segunda fase, mais ampla, permitiu, em nível europeu, maior mobilização na definição dos novos currículos.

2. Projeto Joint Quality Initiative (2001) - organizado pelos governos dos Países Baixos e da Bélgica, reuniu representantes de vários países europeus que definiram novos currículos com caráter ainda muito geral. Os chamados "descritores de Dublin” (2001) são um acordo geral que especifica as competências básicas que os graduados europeus devem adquirir nos três ciclos em que as carreiras vão ser estruturadas.

3. Transnational European Evaluation Project (2001) - outro projeto liderado pela ENQA, com o objetivo de implementar sistemas comuns de avaliação de cursos. Para isso, um grupo de avaliadores realizou a avaliação da mesma carreira em diferentes países, utilizando idêntica metodologia. A experiência foi positiva, mostrando a possibilidade de utilizar critérios comuns em contextos distintos.

4. Quality Culture Project - projeto organizado pela Associação Européia de Universidades (2003) com o objetivo de desenvolver a cultura da qualidade nas instituições de educação superior. Nesse projeto, comitês internacionais avaliaram distintos aspectos da gestão acadêmica de um conjunto de universidades européias, como, por exemplo, gestão da pesquisa, serviços de apoio aos estudantes etc., tratando de identificar critérios de avaliação comuns para universidades com características muito distintas e localizadas em diferentes contextos. 
Tendências das reformas da educação superior na Europa no contexto...

\section{Conclusões}

A cinco anos do início do processo de Bolonha, já se está em condiçôes de realizar uma primeira análise desse processo, tanto por países quanto por temas. Nos países o desenvolvimento do processo foi irregular, e o primeiro país a iniciar esse processo foi Itália, obtendo resultados ambíguos. Por um lado, aumentou de forma evidente a atratividade das universidades a partir do momento em que foram oferecidos cursos com três anos de duração, o que foi constatado pela ampliação do número de matrículas novas. Por outro lado, foi muito baixo o alcance das metas da Declaração de Bolonha, já que nem os créditos europeus nem as mudanças nos objetivos baseados em competências foram desenvolvidos adequadamente.

O processo de Bolonha pode ser considerado mais bem implementado nos Países Baixos. Tanto na França quanto na Alemanha, em razão da resistência de muitas instituiçōes e docentes, foi-lhes dada liberdade para adaptar-se ou não. Nos países anglo-saxóes, como Reino Unido e Irlanda, o processo está mais lento, já que se consideram bem próximos de alcançar os objetivos. $\mathrm{O}$ restante dos países está implementando o processo em ritmos diferenciados, porém todos, em maior ou menor escala, estão comprometidos.

Ao analisar onde estão atualmente os maiores problemas para o desenvolvimento do processo de Bolonha, chega-se às seguintes conclusōes:

(a) Embora as reformas tenham sido extensivas a praticamente todo o Continente Europeu e a todas as instituições de educação superior, ainda não atingiram os estudantes e docentes das instituiçōes universitárias. Tem-se a impressão de que ainda há muito que fazer para conseguir envolver esses atores em um processo tẫo profundo de reforma do modelo educativo. Esse aspecto é particularmente importante porque, como já mencionado, as universidades européias ainda são muito dependentes dos docentes e dos estudantes para a tomada de decisōes. Sem eles é impossível empreender alguma reforma.

(b) Como conseqüência, em parte, do anterior, ainda não foi realizada a necessária mudança nas estruturas educativas, nos métodos de aprendizagem, nos procedimentos de avaliação da 
aprendizagem, no desenvolvimento de cursos mais flexíveis e multidisciplinares etc. Essas mudanças, essenciais para o sucesso do processo, ainda estão em uma fase muito incipiente.

(c) Aumentar a atratividade da educação superior européia exige a implementação de vários mecanismos de reforma como os que já foram citados, porém é imprescindível aumentar os recursos financeiros de que as universidades dispóem para que possam oferecer serviços de qualidade aos estudantes. Não é possível que com o mesmo nível de gasto atual da educação superior européia, que é a metade daquele dos EUA, possa-se alcançar um nível de qualidade semelhante ao desse país. No entanto, a insistência dos estudantes europeus em considerar a educação superior um bem público (quando tecnicamente é um bem semipúblico) não facilita o aporte financeiro de fontes privadas.

(d)Até o momento, foi muito baixa a participação de organizações profissionais no desenvolvimento do currículo das novas carreiras que estão sendo implantadas. Da mesma forma a participação da sociedade em geral, reforçando a tradição das universidades européias de manter-se relativamente à margem da sociedade.

(e) Nas pequenas, mas complexas, transformações instrumentais que fazem, sem dúvida, avançar o projeto, as metas definidas são muitas vezes esquecidas pelos seus participantes, dando a impressão de que nesses cinco anos o mais importante parece ter sido o detalhe e não os objetivos do processo.

A educação superior européia deverá superar alguns desafios importantes num futuro próximo, se quiser alcançar as metas propostas no processo de Bolonha. Alguns desses desafios são:

Em primeiro lugar, a educação superior européia necessita não somente de mais recursos, mas que sejam diversificados. Necessita, fundamentalmente, de mais recursos públicos sob a forma de fundos competitivos que estimulem a eficácia e a eficiência do sistema; necessita também, como afirma o documento da Comissão Européia denominado "O papel das universidades na sociedade do conhecimento" (União Européia, 2003), de mais recursos privados, tanto dos próprios usuários diretos (estudantes e empresas) como de outros (doaçôes sem fins específicos). 
Tendências das reformas da educação superior na Europa no contexto...

Em segundo lugar, é necessário incrementar a eficácia do sistema. Ainda que seja muito cedo para avaliar o efeito das reformas como conseqüência do processo de Bolonha, é preciso insistir na necessidade de reduzir o número de abandonos, encurtar a duração real do tempo de realização do curso e melhorar a relação entre oferta e demanda das competências.

Em terceiro lugar, é necessário avançar na implementação da diversidade institucional. Um sistema educativo superior de massas como o europeu é incompatível com um sistema unificado de universidades, todas com os mesmos objetivos e com a mesma estrutura de oferta e demanda. Diversificar o sistema de educação superior europeu é uma necessidade reconhecida, embora contrária à tradição igualitária da cultura européia.

Em quarto lugar, é necessário melhorar sensivelmente os modelos de governo e de gestão das universidades européias. Reconhece-se que as práticas de gestão habituais nas universidades européias estão longe das "boas práticas". Naturalmente que foram muito poucos os países que se atreveram a romper com as velhas estruturas e renovar os modelos de gestão. Se o atual modelo não for alterado, será difícil as universidades européias converterem-se nas empresas de serviços que a sociedade do conhecimento demanda.

Para finalizar, pode-se afirmar que o processo de Bolonha é resultado de duas forças propulsoras: a exigência de se adaptar à sociedade do conhecimento e de se adequar a um mundo globalizado, onde a europeização é somente o primeiro passo. A Europa comprometeu-se com o mais interessante processo de mudança da educação superior desde o século XIX, quando as universidades européias se ajustaram à era industrial. É possível que nem todos os resultados esperados sejam alcançados, no entanto o processo de reflexão e de mobilização intelectual que está acontecendo neste momento na Europa tem valor por si e, com toda a certeza, fará com que o sistema melhore, pelo menos em longo prazo.

\section{Recebido e aprovado em setembro de 2004.}

\section{Notas}

1. Denomina-se "processo de Bolonha" às atividades desenvolvidas como desdobramento da Declaração de Bolonha, apresentada em detalhes no artigo. 
2. Neste artigo, faz-se referência às universidades européias em geral, porém a maioria das características assinaladas aparece com mais freqüência nas universidades continentais.

3. O termo "acadêmico" é aqui usado no sentido de transmissão de conhecimento e não de desenvolvimento de competências.

\section{Referências bibliográficas}

ALTBACH, P. (Ed.) The changing academic workplace: comparative perspectives. Boston: CIHE, 2000.

ASSOCIAÇÃO EUROPÉIA DE UNIVERSIDADES, 2003. Documento disponível em: <www.eua.be/eua/jsp/en/upload/GrazDecENG. 1066743764824.pdf>.

BERLIN-BOLOGNA, 2003. Documento disponível em: <www. bologna-berlin2003.de/index.htm>

BERLIN COMMUNIQUÉ, 2003. Documento disponível em: <www.bologna-berlin2003.de/pdf/Communique1.pdf>

BOLOGNA DECLARATION, 1999. Documento disponível em: <http://europa.eu.int/comm/education/policies/educ/bologna/ bologna_en.html>.

COMUNICADO DE PRAGA, 2001. Documento disponível em $<$ http://europa.eu.int/comm/education/prague.pdf>.

DESCRITORES DE DUBLIN, 2001. Documento disponível em: $<$ www.jointquality.org/content/ierland/Shared\%20descriptors $\% 20$ $\mathrm{Ba} \% 20 \mathrm{Ma} \cdot \mathrm{doc}>$.

EUROPEAN CREDIT TRANSFER SYSTEM, 2003. Documento disponível em: <http://europa.eu.int/comm/education/programmes/ socrates/ects_en.html>.

ESIB, 2001. Documento disponível em <www.esib.org/>.

MENSAJE DE SALAMANCA, 2001. Documento disponível em $<$ http://eua.uni-graz.at/Salamanca_Message.pdf $>$.

MORA, J.G. Governance and management in the new university. Tertiary Education and Management, n. 7, p. 95-110, 2001. 
Tendências das reformas da educação superior na Europa no contexto...

ORGANIZAÇÃO PARA COOPERAÇÃO E DESENVOLVIMENTO ECONÔMICO (OCDE). Education at a glance. Paris: OECD, 2003.

PROGRAMA ERASMUS, 1988. Documento disponível em: <http:// europa.eu.int/comm/education/programmes/socrates/erasmus/ erasmus_en.html>.

PROGRAMA ERASMUS Mundus, 2004. Documento disponível em: <http://europa.eu.int/comm/education/programmes/mundus/ index_en.html>.

PROJETO TUNING, 2001. Documento disponível em: <www.relint. deusto.es/TuningProject/index.htm>.

PROJETO JOINT QUALITY INITIATIVE, 2001. Documento disponível em: <www.jointquality.org/>.

QUALITY CULTURE PROJECT, 2003. Documento disponível em: www.eua.be/eua/en/ projects_quality.jsp

SUPLEMENTO DO DIPLOMA, 2003. Documento disponível em: $<$ www.europa.eu.int/comm/education/policies/rec_qual/recognition/ diploma_en.html>.

TRANSNATIONAL EUROPEAN EVALUATION PROJECT, 2001. Documento disponível em: <www.enqa.net/texts/TEEPmethod.pdf>.

UNIĀO EUROPÉIA, 2003. Documento disponível em: <http:// europa.eu.int/eur-lex/es/com/cnc/2003/com2003_0058es01.pdf>.

UNIÃO EUROPÉIA, REUNIÃO DE LISBOA, 2000. Documento disponível em: <http://ue.eu.int/ueDocs/cms_Data/docs/pressData/ es/ec/00100-r1.es0.htm>.

UNIÃO EUROPÉIA, REUNIÃO DE BARCELONA, 2002. Documento disponível em: <http://ue.eu.int/ueDocs/ cms_Data/docs/ pressData/es/ec/70829.pdf>. 